\title{
IL-17 in synovial fluids from patients with rheumatoid arthritis is a potent stimulator of osteoclastogenesis
}

\author{
Shigeru Kotake, ${ }^{1}$ Nobuyuki Udagawa, ${ }^{2}$ Naoyuki Takahashi, ${ }^{2}$ Kenichiro Matsuzaki, ${ }^{2}$ \\ Kanami Itoh, ${ }^{2}$ Shigeru Ishiyama, ${ }^{3}$ Seiji Saito, ${ }^{1}$ Kazuhiko Inoue,${ }^{1}$ Naoyuki Kamatani, ${ }^{1}$ \\ Matthew T. Gillespie, ${ }^{4}$ T. John Martin, ${ }^{4}$ and Tatsuo Suda ${ }^{2}$ \\ ${ }^{1}$ The Institute of Rheumatology, Tokyo Women's Medical University, \\ Tokyo 162-0054, Japan \\ ${ }^{2}$ Department of Biochemistry, School of Dentistry, Showa University, Tokyo 142-8555, Japan \\ ${ }^{3}$ The Second Department of Pathology, Tokyo Women's Medical University, Tokyo 162-0054, Japan \\ ${ }^{4}$ St. Vincent's Institute of Medical Research, Fitzroy, Victoria 3065, Australia \\ Address correspondence to: Tatsuo Suda, Department of Biochemistry, School of Dentistry, Showa University, 1-5-8 Hatanodai, \\ Shinagawa-ku, Tokyo 142-8555, Japan. Phone: 81-3-3784-8163; Fax: 81-3-3784-5555; E-mail: suda@dent.showa-u.ac.jp
}

Received for publication November 3, 1998, and accepted in revised form March 22, 1999.

IL-17 is a newly discovered T cell-derived cytokine whose role in osteoclast development has not been fully elucidated. Treatment of cocultures of mouse hemopoietic cells and primary osteoblasts with recombinant human IL-17 induced the formation of multinucleated cells, which satisfied major criteria of osteoclasts, including tartrate-resistant acid phosphatase activity, calcitonin receptors, and pit formation on dentine slices. Direct interaction between osteoclast progenitors and osteoblasts was required for IL-17-induced osteoclastogenesis, which was completely inhibited by adding indomethacin or NS398, a selective inhibitor of cyclooxgenase-2 (COX-2). Adding IL-17 increased prostaglandin $\mathrm{E}_{2}$ $\left(\mathrm{PGE}_{2}\right)$ synthesis in cocultures of bone marrow cells and osteoblasts and in single cultures of osteoblasts, but not in single cultures of bone marrow cells. In addition, IL-17 dose-dependently induced expression of osteoclast differentiation factor (ODF) mRNA in osteoblasts. ODF is a membrane-associated protein that transduces an essential signal(s) to osteoclast progenitors for differentiation into osteoclasts. Osteoclastogenesis inhibitory factor (OCIF), a decoy receptor of ODF, completely inhibited IL17-induced osteoclast differentiation in the cocultures. Levels of IL-17 in synovial fluids were significantly higher in rheumatoid arthritis (RA) patients than osteoarthritis (OA) patients. Anti-IL-17 antibody significantly inhibited osteoclast formation induced by culture media of RA synovial tissues. These

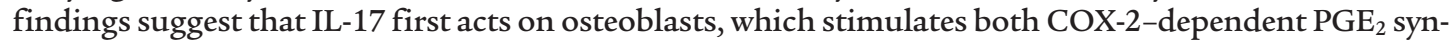
thesis and ODF gene expression, which in turn induce differentiation of osteoclast progenitors into mature osteoclasts, and that IL-17 is a crucial cytokine for osteoclastic bone resorption in RA patients.

J. Clin. Invest. 103:1345-1352 (1999).

\section{Introduction}

Bone-resorbing osteoclasts are of hemopoietic cell origin, probably of the CFU-M-derived monocytemacrophage family (1). Osteoclasts are large multinucleated giant cells that express tartrate-resistant acid phosphatase (TRAP) activity and calcitonin receptors and have the ability to form resorption pits on dentine slices (2-4). In the process of osteoclast differentiation, there is an absolute requirement for cell-cell contact between osteoclast progenitors and bone marrow stromal cells or calvaria-derived osteoblasts (5-8).

We developed a mouse coculture system of hemopoietic cells and primary osteoblasts to investigate osteoclast formation in vitro. In this coculture system, several systemic and local factors were capable of inducing osteoclast-like multinucleated cell (OCL) formation (6-9). These boneresorbing factors were classified into 3 categories according to their signal transduction pathways: (a) 1 $\alpha, 25$-dihydroxyvitamin $\mathrm{D}_{3}\left[1 \alpha, 25(\mathrm{OH})_{2} \mathrm{D}_{3}\right]$ induced OCL formation via $1 \alpha, 25(\mathrm{OH})_{2} \mathrm{D}_{3}$ receptors (VDR) present in the nuclei; (b) parathyroid hormone (PTH), PTH-related protein (PTHrP), prostaglandin $\mathrm{E}_{2}\left(\mathrm{PGE}_{2}\right)$, and IL-1 induced OCL formation via the A kinase system; and (c) IL-11, oncostatin M, leukemia inhibitory factor, and IL- 6 in the presence of soluble IL- 6 receptors, all of which transduce their signals through a signal-transducing gp130 protein, also induced OCL formation in vitro. We reported previously that the target cells of IL- 6 are osteoblasts/stromal cells but that they are not osteoclast precursors in inducing osteoclast differentiation (10). Similarly, coculture experiments using VDR knockout mice and PTH/PTHrP receptor knockout mice have indicated that the signals mediated by $1 \alpha, 25(\mathrm{OH})_{2} \mathrm{D}_{3}$ and $\mathrm{PTH}$, respectively, are also transduced into osteoblasts/stromal cells, but not into osteoclast precursors, to induce osteoclast formation $(11,12)$. Thus, it is concluded that the signals induced by all bone-resorbing factors are transduced into osteo-blasts/stromal cells to induce osteoclast formation. Our hypothesis proposes that osteoblasts/stromal cells express a critical common mediator named osteoclast differentiation factor (ODF), a membrane-bound factor that promotes differentiation of osteoclast progenitors into osteoclasts in response to various bone-resorbing factors through a mechanism involving cell-cell contact $(6,8)$. 


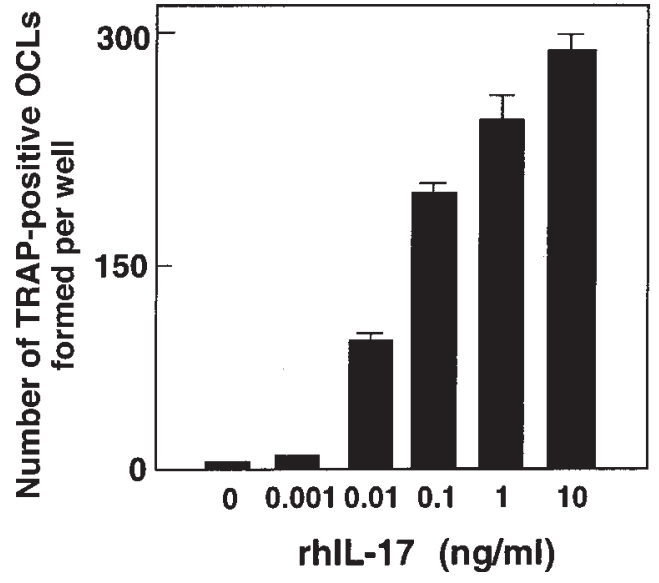

Figure 1

$\mathrm{OCL}$ formation in cocultures of mouse bone marrow cells and osteoblasts in the presence of increasing concentrations of IL-17. After culture for 6 days, TRAP-positive OCLs were counted. Data are expressed as the means \pm SEM of quadruplicate cultures. Experiments were repeated 10 times with similar results.

Tsuda et al. (13) recently cloned an osteoclastogenesis inhibitory factor (OCIF) that markedly inhibited OCL formation in mouse cocultures. OCIF was identical to osteoprotegerin (OPG) $(14,15)$ and TR1 $(16,17)$. OCIF/OPG/TR1 was a secreted member of the TNF receptor family and inhibited osteoclast differentiation by preventing cell-cell interaction between osteoclast progenitors and bone marrow-derived stromal cells $(13-15,17)$. Discovery of OCIF facilitated the molecular cloning of ODF, which stimulated OCL differentiation in the absence of stromal cells (18). ODF was a ligand of OCIF and was found to be identical to TRANCE/ RANKL/OPGL (18-21). TRANCE increased dendritic cell-mediated T-cell proliferation (22). Thus, ODF appears to be an important regulator of both osteoclastogenesis and immune response.

Rheumatoid arthritis (RA) is a chronic inflammatory disease characterized by the destruction of articular cartilage and bone (23). The levels of monocyte-macrophagederived cytokines such as IL-1, IL-6, and soluble IL-6 receptor are elevated in the synovial fluids of RA patients, suggesting that osteoclastogenesis occurs in the joints (24). The role of T cells in the pathogenesis of RA at the chronic stage, however, has not yet been determined, because $\mathrm{T}$ cell-derived cytokines such as IL- 2 or IFN- $\gamma$ are hardly detectable in the synovial tissues and fluids $(25,26)$.

IL-17 is a recently cloned cytokine that is secreted by activated memory $\mathrm{CD}^{+} \mathrm{T}$ cells and modulates the early stage of immune responses (27). Rouvier et al. (28) have cloned cytotoxic $T$ lymphocyte-associated antigen-8 (rat IL-17) from a T-cell subtraction library. Mouse IL-17 was subsequently cloned from a thymus-derived, activated Tcell cDNA library (29). Furthermore, 2 independent groups have cloned the human counterpart of mouse IL17 (30-32). Fossiez et al. (32) reported that IL-17 stimulated epithelial, endothelial, and fibroblastic stromal cells to secrete several cytokines, including IL-6, IL-8, G$\mathrm{CSF}$, and $\mathrm{PGE}_{2}$. In addition, IL-17 greatly promoted the proliferation of $\mathrm{CD} 4^{+}$hemopoietic progenitors in cocultures of synovial fibroblastic cells collected from patients with RA (32). These findings suggest that IL-17 may be a major regulator responsible for the communication between $\mathrm{T}$ cells and hemopoietic cells.

In the present study, we examined a potential role of IL-17 in osteoclastogenesis using a mouse coculture system. IL-17 greatly stimulated OCL formation via a mechanism involving $\mathrm{PGE}_{2}$ synthesis and ODF gene expression. Also, we show by ELISA that IL-17 levels are significantly elevated in the synovial fluids of RA patients compared with those of osteoarthritis (OA) patients. Anti-IL-17 antibody significantly inhibited OCL formation in cocultures with the culture media of RA synovial tissues. Moreover, immunostaining of the synovial tissues of RA patients demonstrated that IL17-positive cells are detected in a subset of $\mathrm{CD}^{+}$, $\mathrm{CD}^{2} 5 \mathrm{RO}^{+} \mathrm{T}$ cells in these patients. These findings suggest that IL-17 present in the synovial tissues and fluids of RA patients may be involved in joint destruction.

\section{Methods}

Animals and drugs. Five- to 8-week-old male ddY mice and newborn ddY mice were obtained from Shizuoka Laboratories Animal Center (Shizuoka, Japan). Recombinant human IL-17 (rhIL-17) was purchased from PeproTech EC Ltd. (London, United Kingdom). Anti-human IL-17 polyclonal antibody (goat $\operatorname{IgG}$ ) and recombinant murine TNF- $\alpha$ were purchased from R\&D Systems Inc. (Minneapolis, Minnesota, USA). Recombinant human IL-1 $\beta$ was purchased from Genzyme Pharmaceuticals (Cambridge, Massachusetts, USA). $1 \alpha, 25(\mathrm{OH})_{2} \mathrm{D}_{3}$ and $\mathrm{PGE}_{2}$ were obtained from Wako Pure Chemical Industries Ltd. (Osaka, Japan). Synthetic human PTH(1-34) was provided by Asahi Chemical Industry (Tokyo, Japan). NS398 was purchased from Calbiochem-Novabiochem Corp. (La Jolla, California, USA). ${ }^{125}$ I-labeled human calcitonin was obtained from Amersham Pharmacia Biotech (Buckinghamshire, United Kingdom). Recombinant human OCIF and cDNA probes for mouse ODF and OCIF were provided by Snow Brand Milk Products Co. (Tochigi, Japan) $(15,18,33)$. Other chemicals and reagents were of analytical grade.

Mouse coculture system for osteoclastogenesis. To prepare primary osteoblasts, a total of 20-30 pieces of calvaria collected from newborn mice were digested with $0.1 \%$ collagenase (Wako Pure

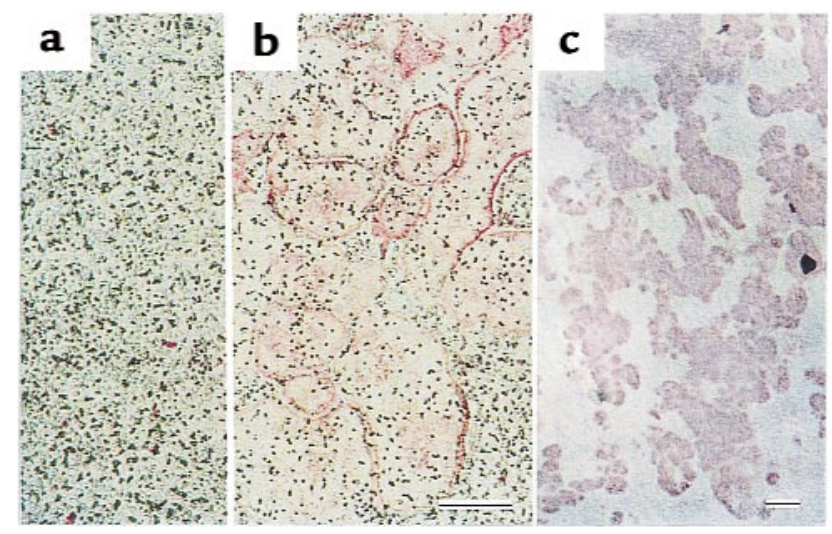

\section{Figure 2}

IL-17 induces OCL formation in cocultures of mouse bone marrow cells and osteoblasts in response to IL-17. (a) Control culture without IL-17. (b) Morphology of OCLs formed in coculture on day 6 in the presence of $1 \mathrm{ng} / \mathrm{mL}$ of IL-17. (c) Resorption pits formed on a dentine slice. Scale bars: $200 \mu \mathrm{m}$. 


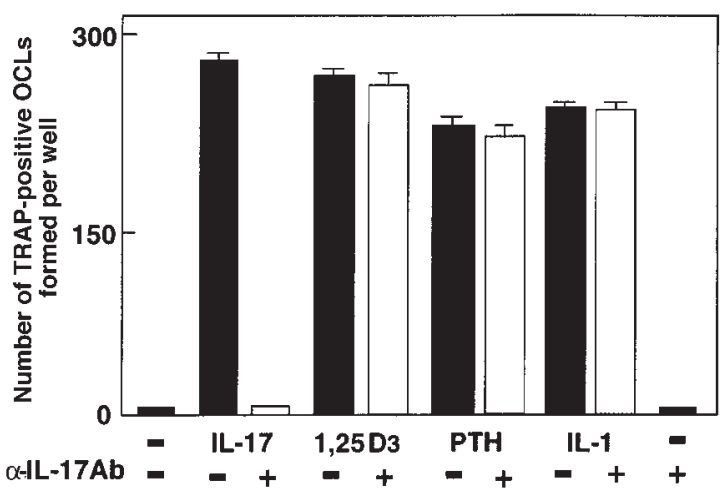

Figure 3

Effect of neutralizing antibody against IL-17 on OCL formation in cocultures of mouse bone marrow cells and osteoblasts in the presence of IL$17(1 \mathrm{ng} / \mathrm{mL}), 1 \alpha, 25(\mathrm{OH})_{2} \mathrm{D}_{3}\left(10^{-8} \mathrm{M}\right)$, PTH $(200 \mathrm{ng} / \mathrm{mL})$, and IL- $1 \beta(10$ $\mathrm{ng} / \mathrm{mL})$. Concentrations of antibody against IL-17 were $2.5 \mu \mathrm{g} / \mathrm{mL}$ for experiments with IL-17 and $5 \mu \mathrm{g} / \mathrm{mL}$ for those with $1 \alpha, 25(\mathrm{OH})_{2} \mathrm{D}_{3}, \mathrm{PTH}$, and $\mathrm{PGE}_{2}$. After culture for 6 days, TRAP-positive OCLs were counted. Data are expressed as the means \pm SEM of quadruplicate cultures. Experiments were repeated 5 times with similar results.

Chemical Industries Ltd.) and 0.2\% dispase (Godo Shusei, Tokyo, Japan). Bone marrow cells were obtained from adult mice. Osteoblasts were cocultured with bone marrow cells as described (34). In short, primary osteoblasts $\left(2 \times 10^{4}\right.$ per well $)$ and nucleated bone marrow cells $\left(5 \times 10^{5}\right.$ per well $)$ were cocultured in 48 -well plates (Corning Glass Inc., Corning, New York, USA) with $0.3 \mathrm{~mL}$ of $\alpha$-MEM (GIBCO BRL, Gaithersburg, Maryland) containing $10 \%$ FBS (JRH Biosciences, Lenexa, Kansas, USA) in the presence of test chemicals. Cultures were incubated in quadruplicate, and cells were replenished on day 3 with fresh medium. OCL formation was evaluated after culture for 6-7 days. In some experiments, an intercell with a membrane filter $(0.45-\mu \mathrm{m}$ pore size $)$ at the bottom (Falcon 3090 cell culture insert; Becton-Dickinson and Co., Lincoln Park, New Jersey, USA) was used to examine the requirement for cell-cell contact. Adherent cells were fixed and stained for TRAP, and the number of TRAP-positive OCLs was scored as described (34). For TRAP staining, adherent cells were fixed with $10 \%$ formaldehyde in PBS for 3 minutes. After treatment with ethanol/acetone (50:50 vol/vol) for 1 minute, the well surface was air dried and incubated for 10 minutes at room temperature in an acetate buffer $(0.1 \mathrm{M}$ sodium acetate, $\mathrm{pH}$ 5.0) containing $0.01 \%$ naphthol AS-MS phosphate (Sigma Chemical Co., St. Louis, Missouri, USA) as a substrate and $0.03 \%$ red violet LB salt (Sigma Chemical Co.) as a stain for the reaction product in the presence of $50 \mathrm{mM}$ sodium tartrate. TRAP-positive cells appeared dark red. TRAP-positive multinucleated cells containing more than 3 nuclei were counted as OCLs. Expression of calcitonin receptors was assessed by autoradiography using ${ }^{125} \mathrm{I}$ labeled human calcitonin as described (35). After bone marrow cells and osteoblasts were cocultured for 8 days on dentine slices, resorption pits were viewed by staining with Meyer's hematoxylin as described previously (35).

Measurement of the $P G E_{2}$ content in culture media. The concentration of $\mathrm{PGE}_{2}$ in culture media was determined using an enzyme immunoassay (EIA; Amersham Pharmacia Biotech) (36). The antibody had the following cross-reactivity when calculated by the bound/free ratio: $\mathrm{PGE}_{2}, 100 \% ; \mathrm{PGE}_{1}, 7.0 \%$; 6keto-PGE $1 \alpha, 5.4 \%$; $\mathrm{PGF}_{2 \alpha}, 4.3 \%$; and $\mathrm{PGD}_{2}, 1.0 \%$.

Patients. Ten male and 33 female patients who satisfied the American Rheumatism Association Criteria (37) for definite or classic RA were studied. Control individuals included 9 OA, 4 trauma, and 7 gout patients. All gout patients had acute gouty arthritis. Informed consent for subsequent procedures was obtained from all patients.

Tissue samples. Synovial tissues were obtained at the time of total knee replacement performed on $12 \mathrm{RA}$ and $3 \mathrm{OA}$ patients. A part of each tissue was dissected into 3 small pieces $(1 \mathrm{~g})$ for organ culture and rinsed well with PBS ( $\mathrm{pH}$ 7.4). Each piece of the synovial tissue was cultured in $1 \mathrm{~mL}$ of RPMI-1640 (GIBCO BRL, Gaithersburg, Maryland, USA) containing $100 \mathrm{U} / \mathrm{mL}$ of penicillin, $10 \mu \mathrm{g} / \mathrm{mL}$ of streptomycin, and $2 \mathrm{mM}$ L-glutamine for 3 days in $5 \% \mathrm{CO}_{2}$ in air at $37^{\circ} \mathrm{C}$. Culture supernatants were collected and kept frozen at $-80^{\circ} \mathrm{C}$ until use for measurement of the IL-17 content by an ELISA kit (BioSource International, Camarillo, California, USA). The mean value of the concentration of the IL-17 of 3 synovial pieces from a single joint was calculated. Frozen sections were prepared from each patient and used for immunohistologic and TRAP staining.

The culture media of synovial tissues $(40 \mu \mathrm{l})$ from RA patients were added together with or without anti-human IL17 antibody $(1 \mu \mathrm{g} / \mathrm{mL})$ to the cocultures $(200 \mu \mathrm{l})$ of osteoblasts and bone marrow cells. After culture for 7 days, the number of TRAP-positive OCLs was counted. No OCLs were formed in the control cultures treated with rabbit IgG $(5 \mu \mathrm{g} / \mathrm{mL}$; Endogen Inc., Woburn, Massachusetts, USA). We used the culture media of synovial tissues rather than synovial fluids to examine the effect of cytokines produced by the same amount of synovial tissues collected from different RA patients.

IL-17 in the synovial fluids. Synovial fluids were obtained from 43 RA patients, 9 OA patients, 4 trauma patients, and 7 gout patients by arthrocentesis into heparinized vials. The synovial fluids $(10 \mathrm{~mL})$ were then treated with hyaluronidase $(0.3 \mathrm{~mL}$, $200 \mathrm{U} / \mathrm{mL}$; Mochida, Tokyo, Japan) to reduce viscosity. The amount of IL-17 in the synovial fluids was measured using an ELISA kit (BioSource International) according to the manufacturer's instructions.

Immunobistologic staining. Specimens of synovial tissue fixed in OCT compound and frozen were cut into sections $(7 \mu \mathrm{m})$. Endogenous and exogenous peroxidase activities were blocked by placing tissues sections in $1 \%$ periodic acid at room temperature for 10 minutes and then washing them thoroughly with PBS. For double staining, anti-IL-17 antibody (R\&D Systems Inc.) and CD4, CD8, and CD45RO (DAKO A/S, Glostrup, Denmark) were used as primary antibodies at 1:300 and 1:50 dilutions, respectively, with incubation overnight at $4{ }^{\circ} \mathrm{C}$. For the secondary anti-

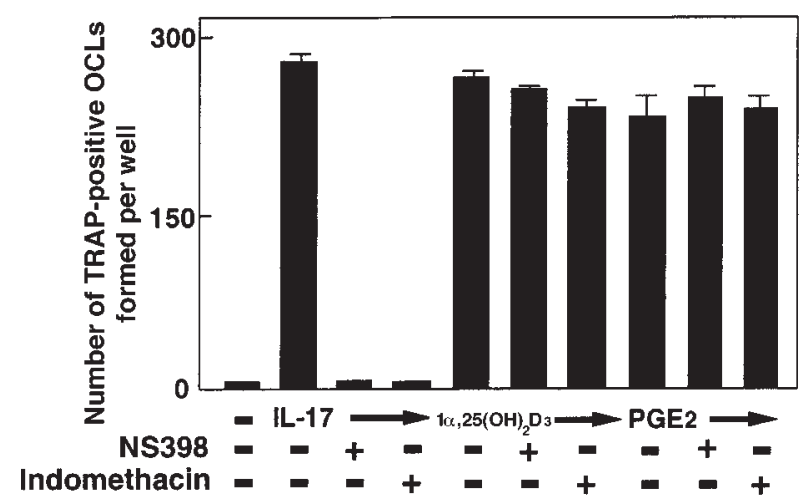

Figure 4

Effect of NS398 $\left(10^{-8} \mathrm{M}\right)$ or indomethacin $\left(10^{-8} \mathrm{M}\right)$ on OCL formation in cocultures of mouse bone marrow cells and osteoblasts in the presence of IL-17 $(1 \mathrm{ng} / \mathrm{mL}), 1 \alpha, 25(\mathrm{OH})_{2} \mathrm{D}_{3}\left(10^{-8} \mathrm{M}\right)$, and $\mathrm{PGE}_{2}\left(10^{-6} \mathrm{M}\right)$. After culture for 6 days, TRAP-positive OCLs were counted. Data are expressed as the means \pm SEM of quadruplicate cultures. Experiments were repeated 7 times with similar results. 
Table 1

Effects of anti-human IL-17 antibody on TRAP-positive OCL formation induced by the culture media of synovial tissues or synovial fluids from RA or OA patients

Concentration of IL-17 in culture media or synovial fluids $(\mathrm{pg} / \mathrm{ml})$
Patients

$\begin{array}{lc}\text { RA no. } 27 & 5.7 \\ \text { RA no. } 60 & 12.5 \\ \text { RA no. } 96 & \text { ND }\end{array}$

RA no. 27

5.7

ND

Culture media of synovial tissues

Exp. 1

RA no. 9

16.0

35.7

OA no. 1 ND

OA no. 2 ND

Exp. 2

RA no. $7 \quad 16.0$

RA no. 9

OA no. 3 ND

OA no. 4
Number of TRAP-positive OCLs formed per well Anti-human IL-17 antibody

- +

$\begin{array}{cc}6.7 \pm 1.1 & 2.0 \pm 0.3^{\mathrm{A}} \\ 12.6 \pm 0.7 & 4.0 \pm 0.5^{\mathrm{A}}\end{array}$

0

0
ND

$\begin{array}{cc}84.3 \pm 5.6 & 10.5 \pm 3.2^{\mathrm{A}} \\ 110.5 \pm 8.6 & 23.0 \pm 3.7^{\mathrm{A}} \\ 0 & 0 \\ 0 & 0 \\ 107.3 \pm 5.4 & 22.8 \pm 3.1^{\mathrm{A}} \\ 121.8 \pm 7.9 & 31.0 \pm 5.2^{\mathrm{A}} \\ 0 & 0 \\ 0 & 0\end{array}$

The culture media of synovial tissues $(40 \mu \mathrm{l})$ or synovial fluids $(20 \mu \mathrm{l})$ from RA or OA patients were added together with $(+)$ or without $(-)$ anti-human IL-17 antibody $(1$ $\mu \mathrm{g} / \mathrm{ml})$ to the cocultures $(200 \mu \mathrm{l})$ of osteoblasts and bone marrow cells. After culture for 7 days, the number of TRAP-positive OCLs was counted. Data are expressed as the means \pm SEM of quadruplicate cultures. No OCLs were formed in the coculture without the culture media of synovial tissues. ${ }^{A}$ Significantly different from the cultures treated without antibody $P<0.0001$. ND, none detectable.

body, anti-goat IgG-conjugated peroxidase (Medical and Biological Laboratories, Nagoya, Japan) (1:300 dilution) was first used with incubation at room temperature for 60 minutes, and it developed color using 3,3'-diaminobenzidine tetrahydrochloride (DAB). Next, for the secondary antibody, FITC-conjugated mouse immunoglobulins (DAKOPATTS Japan Ltd., Kyoto, Japan) (1:300 dilution) were used with incubation at room temperature for 3 hours. They were examined by light and fluorescence microscopy.

Northern blot analysis. Total cellular RNA was extracted from osteoblasts using Trizol (GIBCO BRL). For Northern blotting, $20 \mu \mathrm{g}$ of total RNA was resolved by electrophoresis in a $1 \%$ agarose-formaldehyde gel and was transferred onto a Hybond$\mathrm{N}$ membrane (Amersham Life Sciences Inc., Arlington Heights,

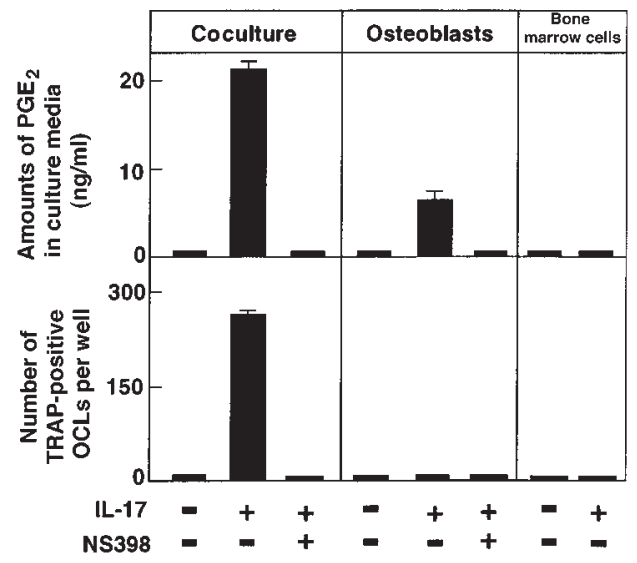

Figure 5

Effect of NS398 $\left(10^{-8} \mathrm{M}\right)$ on OCL formation and $\mathrm{PGE}_{2}$ production in cocultures and separate cultures of osteoblasts and bone marrow cells in the absence or presence of IL-17 $(1 \mathrm{ng} / \mathrm{mL})$. After culture for 6 days, TRAP-positive OCLs were counted. Data are expressed as the means \pm SEM of quadruplicate cultures. Experiments were repeated 5 times with similar results.
Illinois, USA). The membrane was hybridized with ${ }^{32} \mathrm{P}-$ labeled cDNA probes for mouse ODF (18), OCIF (15), and $\beta$-actin. The hybridized probes were removed from the membrane by boiling in $0.2 \%$ SDS and then sequentially rehybridized with the respective probes.

Statistical analysis. The data were analyzed by a Kruskal-Wallis test, a Mann-Whitney $U$ test, and Student's $t$ test (StatView; Abacus Concepts Inc., Berkeley, California, USA). The significance of difference was defined as $P<0.01$. All values were represented as the means \pm SEM, or box plots, in which the upper and the lower bars show the 90th and 10th percentiles, respectively, and the upper, center, and lower lines of the box show 75 th, 50 th, and 25 th percentiles, respectively.

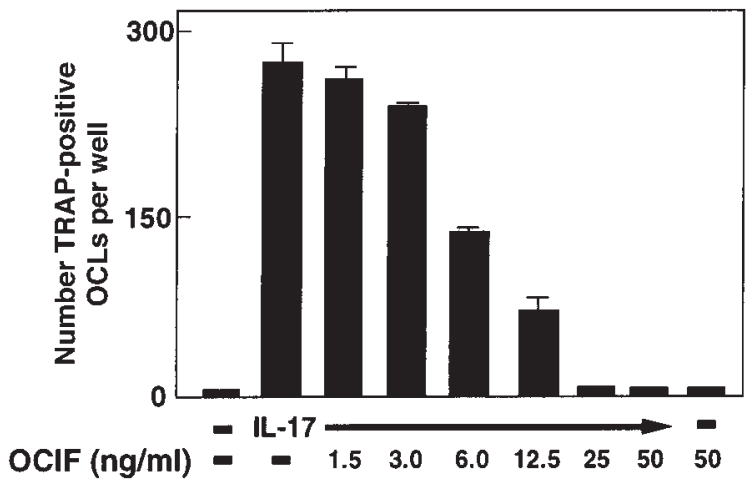

Figure 6

Effect of OCIF (1.5-50 ng/mL) on OCL formation in cocultures of mouse bone marrow cells and osteoblasts in the presence of IL-17 $(1 \mathrm{ng} / \mathrm{mL})$. After culture for 6 days, TRAP-positive OCLs were counted. Data are expressed as the means \pm SEM of quadruplicate cultures. Experiments were repeated 3 times with similar results. 


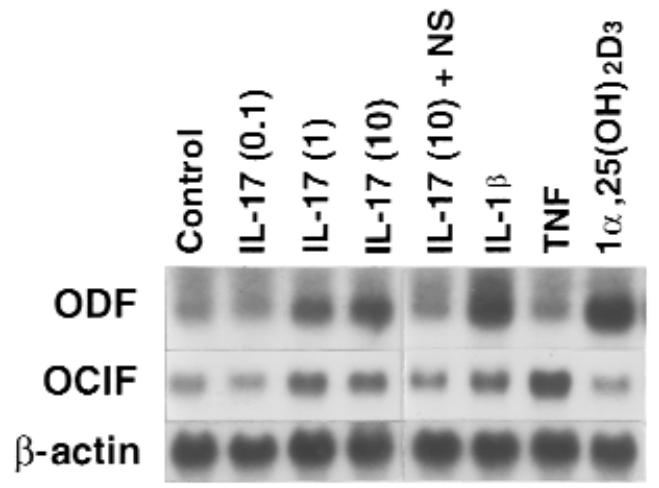

Figure 7

Expression of ODF mRNA by IL-17. A blot loaded with $20 \mu \mathrm{g}$ of total RNA from mouse osteoblasts cultured for 3 days in the absence or presence of various concentrations of IL-17 (0.1-10 ng/mL), NS398 $\left(10^{-8} \mathrm{M}\right)$, IL-1 $\beta$ $(1 \mathrm{ng} / \mathrm{mL}), \mathrm{TNF}-\alpha(10 \mathrm{ng} / \mathrm{mL})$, and $1 \alpha, 25(\mathrm{OH})_{2} \mathrm{D}_{3}\left(10^{-8} \mathrm{M}\right)$ was probed with ODF, OCIF, or $\beta$-actin. NS, NS398.

\section{Results}

Figure 1 shows TRAP-positive OCL formation in response to IL-17 in cocultures of mouse bone marrow cells and osteoblasts. Treatment with rhIL-17 for the entire 6 days in culture dose-dependently stimulated TRAP-positive OCL formation (Figures 1 and 2b). An autoradiographic study using labeled calcitonin revealed that TRAP-positive multinucleated cells formed in the cocultures possessed calcitonin receptors (data not shown). When bone marrow cells and osteoblasts were cocultured on dentine slices in the presence of IL-17, numerous resorption pits were formed (Figure 2c). A polyclonal anti-IL-17 antibody (at $2.5 \mu \mathrm{g} / \mathrm{mL}$ ) completely inhibited the IL-17 effect on OCL formation (Figure 3). A higher concentration (at $5 \mu \mathrm{g} / \mathrm{mL}$ ) of IL-17 antibody, however, did not inhibit the OCL formation induced by $1 \alpha, 25(\mathrm{OH})_{2} \mathrm{D}_{3}, \mathrm{PTH}$, or IL-1.

When osteoblasts and bone marrow cells were cocultured without direct contact using a membrane filter, no TRAP-positive cells were formed in response to IL-17 (data not shown). This indicates that a membrane-associated factor is involved in the IL-17-induced OCL formation. Moreover, the OCL formation induced by IL-17 was completely inhibited by adding indomethacin or NS398, a selective inhibitor of cyclooxgenase-2 (COX-2) (Figure 4). Osteoclastogenesis induced by $1 \alpha, 25(\mathrm{OH})_{2} \mathrm{D}_{3}$ or $\mathrm{PGE}_{2}$ was not inhibited by indomethacin or NS398 (Figure 4). These findings suggest that IL-17 induces OCL formation by a mechanism involving $\mathrm{PGE}_{2}$.

Figure 5 shows the amounts of $\mathrm{PGE}_{2}$ released into culture media in cocultures of osteoblasts and bone marrow cells. $\mathrm{PGE}_{2}$ was also measured in separate cultures of osteoblasts or bone marrow cells. rhIL-17 increased the $\mathrm{PGE}_{2}$ content in culture media in separate cultures of osteoblasts, but not of bone marrow cells, and this was further enhanced in the cocultures (Figure 5). The IL-17-induced $\mathrm{PGE}_{2}$ production was correlated with OCL formation in the cocultures. NS398, a COX-2 selective inhibitor, blocked both $\mathrm{PGE}_{2}$ production and OCL formation (Figure 5).
The IL-17-induced OCL formation was dose-dependently inhibited by OCIF, a decoy receptor for ODF, which is induced on the plasma membrane of osteoblasts in response to several bone-resorbing factors (Figure 6). This suggests that ODF is a key factor for OCL formation induced by IL-17 as well. Indeed, IL-17 dose-dependently induced ODF mRNA expression in osteoblasts (Figure 7). IL- $1 \beta$ and $1 \alpha, 25(\mathrm{OH})_{2} \mathrm{D}_{3}$ also induced ODF mRNA expression in osteoblasts. NS398 inhibited the expression of ODF mRNA by IL-17 (Figure 7). These findings suggest that IL-17-induced OCL formation occurs by a mechanism involving $\mathrm{PGE}_{2}$ production, which in turn stimulates the production of ODF. On the other hand, OCIF mRNA was constitutively expressed in osteoblasts in the presence or absence of bone-resorbing factors (Figure 7).

To examine the role of IL-17 in the pathogenesis of RA, IL-17 in synovial fluids obtained from patients with RA, OA, trauma, or gout was measured. The concentration of IL-17 in the synovial fluids was significantly higher in RA patients than OA patients $(P<0.0001)$ (Figure 8a). In the culture of synovial tissues, the culture media from RA patients contained significantly more IL-17 than those from OA patients $(P=0.009)$.

a

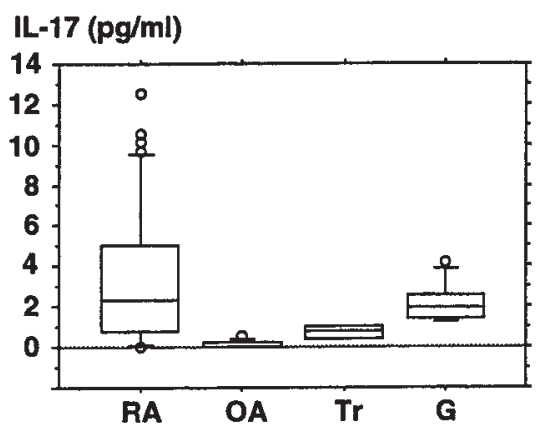

b

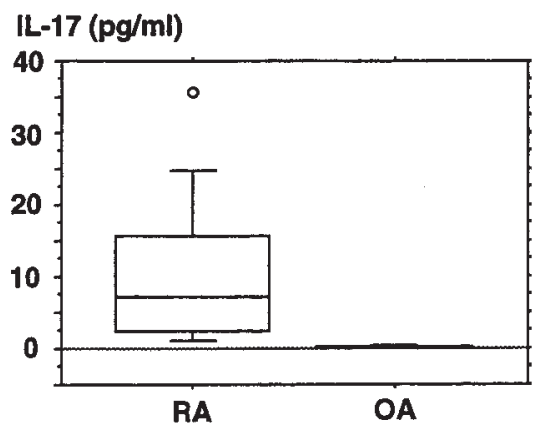

\section{Figure 8}

Concentrations of IL-17 in the synovial fluids (a) or culture media of synovial tissues (b) from RA, OA, trauma, and gout patients. Synovial fluids were obtained from 43 RA, 9 OA, 4 trauma, and 7 gout patients (a). Synovial tissues were obtained from $12 \mathrm{RA}$ and $3 \mathrm{OA}$ patients (b). A part of the tissue was dissected into small pieces $(1 \mathrm{~g})$, rinsed well with PBS ( $\mathrm{pH}$ 7.4), and cultured in $1 \mathrm{~mL}$ of RPMI- 1640 containing $100 \mathrm{U} / \mathrm{mL}$ of penicillin, $10 \mu \mathrm{g} / \mathrm{mL}$ of streptomycin, and $2 \mathrm{mM}$ L-glutamine for 3 days in $5 \%$ $\mathrm{CO}_{2}$ in air at $37^{\circ} \mathrm{C}$. Culture media were collected, and their concentrations of IL-17 were measured using a ELISA kit for human IL-17. The mean value of the concentration of IL-17 of 3 synovial pieces from a single joint was calculated. The results are expressed as box plots, as described in Methods. Significant differences between RA and OA: $P<0.0001$ (a); $P<0.009$ (b). Tr, trauma; G, gout. 

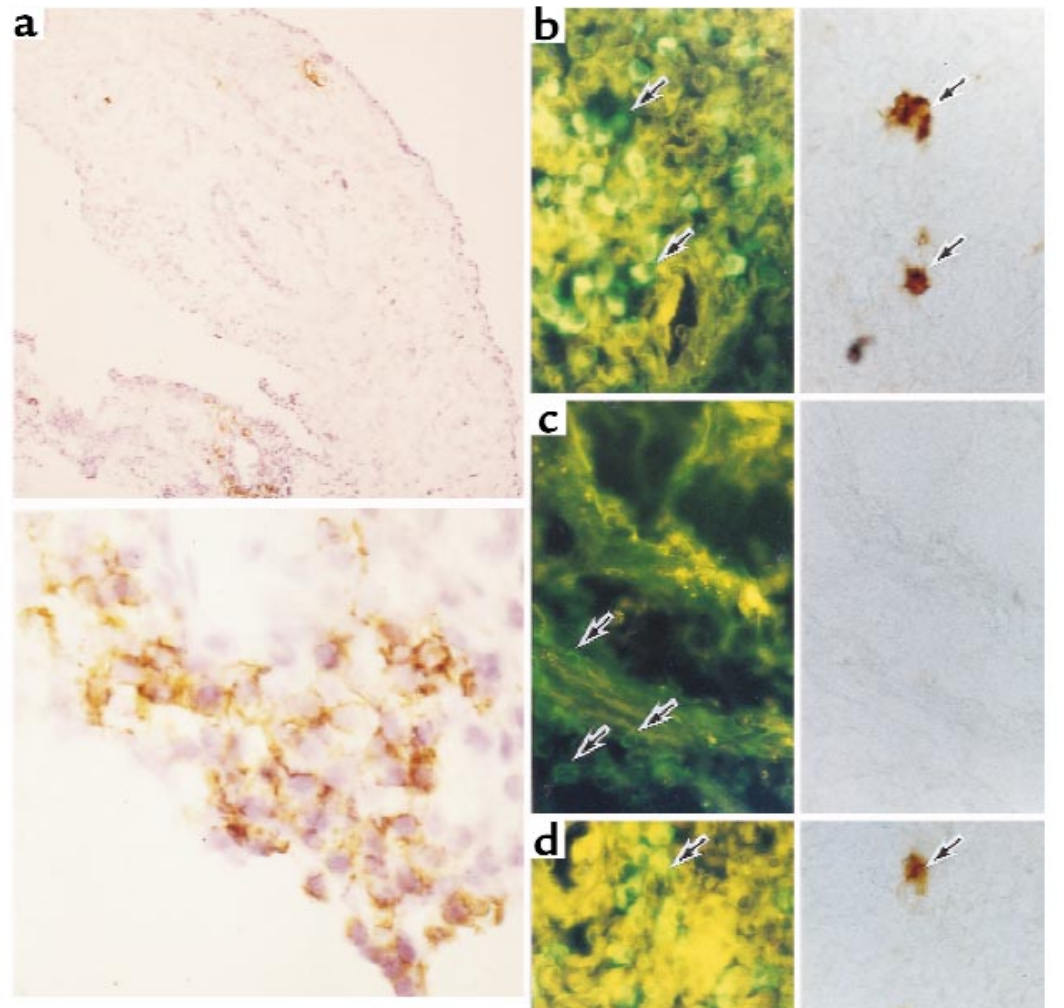

Figure 9

Immunohistochemical staining for IL-17, CD4, CD8, and CD45RO in the synovial tissues of RA patients. Sections were prepared from frozen specimens obtained from RA patients. (a) Sections were stained with antibody against IL-17. The bottom panelof a shows a high-power view of a portion of the top panel of a. Sections from RA patients stained with antibody against IL-17 (right panels) were simultaneously stained with antibodies against CD4 (b), CD8 (c), or CD45RO (d), as viewed with an FITC filter (left panels). Single arrows show stained mononuclear cells. Original magnification: $\times 64$ (top panel of a); $\times 320$ (bottom panel of a); $\times 160$ (b-d).

(Figure 8b). Furthermore, when synovial tissues were immunostained with anti-IL-17 antibody, IL-17-positive mononuclear cells were detected in those from RA patients (Figure 9a) but not in those from OA patients. In general, $\mathrm{CD}^{+} \mathrm{T}$ cells have helper and inducer functions, whereas $\mathrm{CD}^{+} \mathrm{T}$ cells serve as cytotoxic cells. $\mathrm{CD} 4^{+}$ and $\mathrm{CD}^{+} \mathrm{T}$ cells are classified into naive and memory $\mathrm{T}$ cells by their expression of CD45 isoforms. CD45RA ${ }^{+}$ and $\mathrm{CD} 45 \mathrm{RO}^{+}$phenotypes are associated with naive and memory $T$ cells, respectively. In double staining of the synovial tissues with antibodies against CD4, CD8, or CD45RO, as well as IL-17, a subset of CD $4^{+}$cells (Figure $9 \mathrm{~b}$ ) and a subset of $\mathrm{CD}^{4} 5 \mathrm{RO}^{+}$cells (Figure 9d) were stained with the antibodies against IL-17. CD8 ${ }^{+}$cells, however, were not stained with the antibodies against IL-17 (Figure 9c). Fossiez et al. (32) have reported that IL-17 transcripts can be detected only in T cells upon activation, and mostly in activated $\mathrm{CD}^{+}, \mathrm{CD} 4 \mathrm{RO}^{+}$ memory $\mathrm{T}$ cells. Thus, our results are consistent with their findings, indicating that a subset of $\mathrm{CD}^{+}$, $\mathrm{CD}^{2} 5 \mathrm{RO}^{+}$memory $\mathrm{T}$ cells produces IL-17 in synovial tissues of RA patients.

Synovial fluids from RA patients induced osteoclastogenesis, which was partially inhibited by adding anti-IL17 antibody (Table 1). The weak osteoclast-inductive capacity of RA synovial fluids may be due to the presence of potent inhibitors of osteoclastogenesis such as OCIF, nonsteroidal anti-inflammatory drugs like COX inhibitors, and disease-modifying antirheumatic drugs like gold salts. Thus, the culture media of synovial tissues from RA patients were used to test the biologic significance of synovial tissue-derived IL-17 to induce osteoclastogenesis in the coculture experiments. OCLs were formed in cocultures of osteoblasts and bone marrow cells in response to the culture media of synovial tissues from RA patients but not from OA patients (Table 1). The stimulation of OCL formation induced by the culture media was blocked strikingly by adding anti-IL17 antibody. OCL formation was reduced significantly (80\% reduction; $P<0.0001$ ), whereas control IgG antibody had not effect (Table 1). OCL formation was not induced in cocultures in the absence of culture media of synovial tissues (data not shown). This indicates the importance of synovial tissue-derived IL-17 in invoking osteoclastogenesis.

\section{Discussion}

Recent evidence indicates that ODF, a ligand for OCIF, is expressed as a membrane-associated protein in osteoblasts/stromal cells and that it stimulates murine and human OCL formation in the absence of osteoblasts/stromal cells $(18,21,38)$. Treatment of osteoblasts with $1 \alpha, 25(\mathrm{OH})_{2} \mathrm{D}_{3}, \mathrm{PTH}, \mathrm{PGE}_{2}$, or IL-11 upregulates ODF mRNA expression (18). In the present study, we showed that IL-17 similarly stimulated ODF gene expression in osteoblasts and induced osteo- 


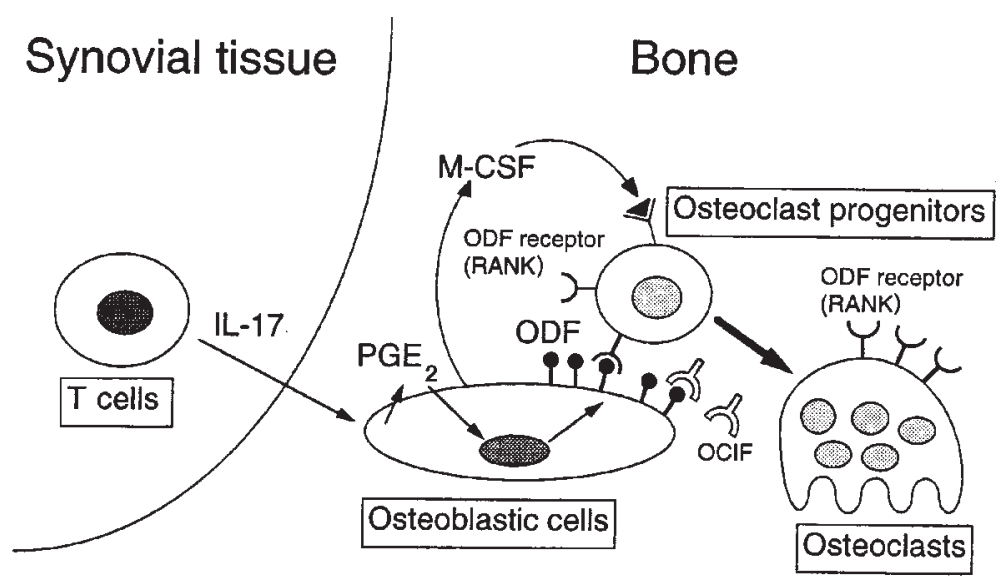

\section{Figure 10}

A possible mechanism of osteoclastogenesis by IL-17 in the affected joint of RA patients. IL-17 produced by $T$ cells in the synovial tissues induces $\mathrm{PGE}_{2}$ synthesis in osteoblasts/stromal cells in the adjacent bone. $\mathrm{PGE}_{2}$ then induces ODF expression in osteoblasts. ODF transduces a signal for osteoclastogenesis through ODF receptor (RANK) expressed on osteoclast progenitors $(18,20)$. M-CSF produced by osteoblasts/stromal cells is also an essential soluble factor for osteoclast differentiation $(7,8,18)$. clast differentiation in cocultures of osteoblasts and bone marrow cells. The osteoclast formation induced by IL-17 was completely blocked by OCIF, a decoy receptor of ODF. We also demonstrated that IL-17 induced $\mathrm{PGE}_{2}$ synthesis by osteoblasts but not by osteoclast progenitors. NS398, a selective inhibitor of COX-2, inhibited not only IL-17-dependent ODF gene expression in osteoblasts but also osteoclast formation in cocultures in response to IL-17. Therefore, it is concluded that IL-17 induces ODF synthesis via $\mathrm{PGE}_{2}$ synthesis by osteoblasts, which in turn stimulates OCL formation (Figure 10).

We reported that IL-18 inhibits osteoclast formation via the production of GM-CSF by T cells $(34,39)$. The precise role of $\mathrm{T}$ cells in bone homeostasis, however, has not been fully elucidated. T cell-derived cytokines that inhibit OCL formation, such as IL-4, IL-10, IFN- $\gamma$, and GM-CSF, have been reported, but $\mathrm{T}$ cell-derived cytokines that induce OCL formation have not been reported before, except for TNF- $\alpha$. In the present study, we demonstrated that IL-17 is produced by T cells and induces osteoclastogenesis. Thus, it is likely that IL-17 is an important regulator of both osteoclastogenesis and immune response.

We also reported that OCLs are present in synovial tissues from RA patients and that IL- 6 and soluble IL- 6 receptors in synovial fluids may be involved in OCL formation (24). It is likely that IL-17 produced by activated memory $\mathrm{T}$ cells in synovial tissues also contributes to OCL formation via $\mathrm{PGE}_{2}$ synthesis and ODF expression in synovial tissues. In the present study, we detected a higher concentration of IL-17 in synovial fluids from RA patients compared with those from OA patients. Moreover, anti-IL-17 antibody greatly inhibited OCL formation in cocultures of bone marrow cells and osteoblasts; this antibody was induced by the culture media of synovial tissues from 2 RA patients whose synovial tissues produced a significant amount of IL-17 (Table 1). In fact, approximately $80 \%$ of the OCL formation was blocked by adding anti-IL-17 antibody, indicating that IL-17 is indeed involved in OCL formation at least in patients whose synovial tissues produce a significant amount of IL-17. Thus, in the adjacent articular bone, as well as in the synovial tissues, IL-17 may induce OCL formation via $\mathrm{PGE}_{2}$ synthesis and ODF expression by osteoblasts.
The role of T cells in the pathogenesis of chronic RA has been a matter of controversy $(25,26,40,41)$. The paucity of $\mathrm{T}$ cell-derived cytokines and the contrasting abundance of monokines have led to the view that RA, at least in its late stage, is a disease in which the key cellular elements are monocytes and synoviocytes. Moreover, MacInnes et al. (42) recently demonstrated that IL-15, which functions just like IL-2 despite IL-15 being a monocyte-derived cytokine, plays an important role in inducing synovial T-cell recruitment and activation. In the present study, however, IL-17-positive cells were detected in a subset of $\mathrm{CD}^{+}, \mathrm{CD}_{45 \mathrm{RO}^{+}}$ $\mathrm{T}$ cells in synovial tissues from RA patients. In addition, increased amounts of IL-17 were detected in synovial fluids from RA patients. Furthermore, Neidhart et al. (43) have recently shown that in patients with high IgM rheumatoid factors, increases in the number of $\mathrm{CD}^{+}, \mathrm{CD}^{4} 5 \mathrm{RA}^{-}, \mathrm{CD}_{45 \mathrm{RO}^{+}}$memory $\mathrm{T}$ cells were correlated with the joint destruction evaluated by Larsen radiographic scores but not with the disease duration. Thus, it is concluded that T cell-derived IL17 may, at least in part, play a role in joint destruction in RA patients.

In summary, IL-17 acts on osteoblasts, resulting in COX-2-mediated $\mathrm{PGE}_{2}$ synthesis and ODF expression, the latter directly inducing differentiation of osteoclast progenitors into mature osteoclasts by binding to ODF receptors present in osteoclast progenitors. IL-17 appears to be involved in not only immune responses but also osteoclastogenesis in RA patients. Excess production of IL-17 by memory T cells may contribute to osteoclastic bone resorption in RA patients. The control of expression of IL-17, ODF, or OCIF in RA patients will provide direction to the development of new treatment strategies for bone destruction in RA patients.

\section{Acknowledgments}

We thank Eijiro Jimi, Taro Tsurukai, Shuichi Akiyama, Toshimasa Shinki (Showa University), and Mariko Sodeoka (Tokyo Women's Medical University) for their valuable technical assistance. This work was supported in part by grants-in-aid (09877355 and 09671905) and the High-Technology Research Center Project from the ministry of Education, Science, Sport and Culture of Japan, and by grants from the Nakatomi Health Science Foundation and the National Health \& Medical Research Council of Australia. 
1. Udagawa, N., et al. 1990. Origin of osteoclasts: mature monocytes and macrophages are capable of differentiating into osteoclasts under a suitable microenvironment prepared by bone marrow-derived stromal cells. Proc. Natl. Acad. Sci. USA. 87:7260-7264.

2. Chambers, T.J. 1992. Regulation of osteoclast development and function. In Biology and physiology of the osteoclast. B.R. Hunter and C.V. Gay, editors. CRC Press. Boca Raton, FL. 105-128.

3. Roodman, G.D. 1996. Advances in bone biology: the osteoclast. Endocr. Rev. 17:308-332.

4. Athanasou, N.A. 1996. Cellular biology of bone-resorbing cells. J. Bone Joint Surg. Am. 78:1096-1112.

5. Rodan, G.A., and Martin, T.J. 1981. Role of osteoblasts in hormonal control of bone resorption: a hypothesis. Calcif. Tissue Int. 33:349-351.

6. Suda, T., Takahashi, N., and Martin, T. J. 1992. Modulation of osteoclast differentiation. Endocr. Rev. 13:66-88.

7. Suda, T., Udagawa, N., and Takahashi, N. 1996. Osteoclast generation. In Principles of bone biology. L.G. Raisz, G.A. Rodan, and J.P. Bilezikian, editors. Academic Press. San Diego, CA. 87-102.

8. Martin, T.J., and Udagawa, N. 1998. Hormonal regulation of osteoclast function. Trends Endocrinol. Metab. 9:6-12.

9. Martin, T.J., Romas, E., and Gillespie, M.T. 1998. Interleukins in the control of osteoclast differentiation. Crit. Rev. Eukaryotic Gene Expr. 8:107-123.

10. Udagawa, N., et al. 1995. Interleukin(IL)- 6 induction of osteoclast differentiation depends on IL- 6 receptors expressed on osteoblastic cells but not on osteoclast progenitors. J. Exp. Med. 182:1461-1468.

11. Liu, B.Y., et al. 1998. Conditionally immortalized murine bone marrow stromal cells mediate parathyroid hormone-dependent osteoclastogenesis in vitro. Endocrinology. 139:1952-1964.

12. Kato, S., Sekine, K., Matsumoto, T., and Yoshizawa, T. 1998. Molecular genetics of vitamin D receptor acting in bone. J. Bone Miner. Metab. 16:65-71.

13. Tsuda, E., et al. 1997. Isolation of a novel cytokine from human fibroblasts that specifically inhibits osteoclastogenesis. Biochem. Biophys. Res. Commun. 234:137-142.

14. Simonet, W.S., et al. 1997. Osteoprotegerin: a novel secreted protein involved in the regulation of bone density. Cell. 89:309-319.

15. Yasuda, H., et al. 1998. Identity of osteoclastogenesis inhibitory factor (OCIF) and osteoprotegerin (OPG): a mechanism by which OPG/OCIF inhibits osteoclastogenesis in vitro. Endocrinology. 139:1329-1337.

16. Tan, K.B., et al. 1997. Characterization of a novel TNF-like ligand and recently described TNF ligand and TNF receptor superfamily genes and their constitutive and inducible expression in hematopoietic and nonhematopoietic cells. Gene. 204:35-46.

17. Kwon, B.S., et al. 1998. TR1, a new member of the tumor necrosis factor receptor superfamily, induces fibroblast proliferation and inhibits osteoclastogenesis and bone resorption. FASEB J. 12:845-854.

18. Yasuda, H., et al. 1998. Osteoclast differentiation factor is a ligand for osteoprotegerin/osteoclastogenesis-inhibitory factor and is identical to TRANCE/RANKL. Proc. Natl. Acad. Sci. USA. 95:3597-3602.

19. Wong, B.R., et al. 1997. TRANCE is a novel ligand of the tumor necrosis factor receptor family that activates c-Jun $\mathrm{N}$-terminal kinase in T cells. $J$. Biol. Chem. 272:25190-25194.

20. Anderson, D.M., et al. 1997. A homologue of the TNF receptor and its ligand enhance T-cell growth and dendritic-cell function. Nature. 390:175-179.

21. Lacey, D.L., et al. 1998. Osteoprotegerin ligand is a cytokine that regulates osteoclast differentiation and activation. Cell. 93:165-176.

22. Wong, B.R., et al. 1997. TRANCE (tumor necrosis factor [TNF]-related activation-induced cytokine), a new TNF family member predominant- ly expressed in T cells, is a dendritic cell-specific survival factor. J. Exp. Med. 185:2075-2080.

23. Wilder, R.L. 1993. Rheumatoid arthritis. Epidemiology, pathology, and pathogenesis. In Primers on the rheumatic diseases. 10th edition. H.R. Shumacher, Jr., editor. The Arthritis Foundation. Atlanta, GA. 86-89.

24. Kotake, S., et al. 1996. Interleukin- 6 and soluble interleukin- 6 receptors in the synovial fluids from rheumatoid arthritis patients are responsible for osteoclast-like cell formation. J. Bone Miner. Res. 11:88-95.

25. Firestein, G.S., and Zvaifler, N.J. 1990. How important are T cells in chronic rheumatoid synovitis. Arthritis Rheum. 33:768-773.

26. Fox, D.A. 1997. The role of $\mathrm{T}$ cells in the immunopathogenesis of rheumatoid arthritis. New perspective. Arthritis Rheum. 40:598-608.

27. Broxmeyer, H.E. 1996. Is interleukin 17, an inducible cytokine that stimulates production of other cytokines, merely a redundant player in a sea of other biomolecules? J. Exp. Med. 183:2411-2415.

28. Rouvier, E., Luciani, M.-F., Mattéi, M.-G., Denizot, F., and Golstein, P. 1993. CTLA-8, cloned from an activated T cell, bearing AU-rich messenger RNA instability sequences, and homologous to a Herpesvirus saiminri gene. J. Immunol. 150:5445-5456.

29 . Kennedy, J., et al. A cytokine preferentially expressed by $\alpha \beta T C R+C D 4-$ CD8-T cells. J. Interferon Cytokine Res. 16:611-617.

30. Yao, Z., et al. 1995. Herpesvirus saimiri encodes a new cytokine, IL-17, which binds to a novel cytokine receptor. Immunity. 3:811-821.

31. Yao, Z., et al. 1995. Human IL-17: a novel cytokine derived from T cells. J. Immunol. 155:5483-5486.

32. Fossiez, F., et al. 1996. T-cell interleukin-17 induces stromal cells to produce proinflammatory and hematopoietic cytokines. J. Exp. Med. 183:2593-2603.

33. Yamaguchi, K., et al. 1998. Characterization of structural domains of human osteoclastogenesis inhibitory factor. J. Biol. Chem. 278:5117-5123.

34. Udagawa, N., et al. 1997. Interleukin-18 (interferon $\gamma$-inducing factor) is produced by osteoblasts and acts via granulocyte/macrophage colonystimulating factor and not via interferon- $\gamma$ to inhibit osteoclast formation. J. Exp. Med. 185:1005-1012.

35. Suda, T., Jimi, E., Nakamura, I., and Takahashi, N. 1997. Role of $1 \alpha, 25-$ dihydroxyvitamin $\mathrm{D}_{3}$ in osteoclast differentiation and function. Methods Enzymol. 282:223-235.

36. Akatsu, T., et al. 1992. Preparation and characterization of a mouse osteoclast-like multinucleated cell population. J. Bone Miner. Res. 7:1297-1306.

37. Ropes, M.W., Bennett, G.A., Cobb, S., Jacox, R., and Jessar, R.A. 1958. Revision of diagnostic criteria for rheumatoid arthritis. Bull. Rheum. Dis. 9:175-176.

38. Matsuzaki, K., et al. 1998. Osteoclast differentiation factor (ODF) induces osteoclast-like cell formation in human peripheral blood mononuclear cell cultures. Biochem. Biophys. Res. Commun. 246:199-204.

39. Horwwood, N.J., et al. 1998. Interleukin 18 inhibits osteoclast formation via $\mathrm{T}$ cell production of granulocyte macrophage colony-stimulating factor. J. Clin. Invest. 101:595-603.

40. Kotake, S., et al. 1997. In vivo gene expression of type 1 and type 2 cytokines in synovial tissue from patients in early stages of rheumatoid, reactive, and undifferentiated arthritis. Proc. Assoc. Am. Physicians. 109:286-301.

41. Dudler, J., and So, A.K.-L. 1998. T cells and related cytokines. Curr. Opin. Rheumatol. 10:207-211.

42. MacInnes, I.B., and Liew, F.Y. 1998. Interleukin 15: a proinflammatory role in rheumatoid arthritis synovitis. Immunol. Today. 19:75-79.

43. Neidhart, M., Fehr, K., Pataki, F., and Michel, B.A. 1996. The levels of memory (CD45RA-, RO+) CD4+ and CD8+ peripheral blood T-lymphocytes correlate with IgM rheumatoid factors in rheumatoid arthritis. Rheumatol. Int. 15:201-209. 